\title{
COVID-19 Pandemic and Bio-Ethical Challenges
}

\author{
Abhishek Singh, ${ }^{1, *}$, Sunny Ohlan', Deepika Agrawal ${ }^{2}$ \\ ${ }^{1}$ Department of Community Medicine, SHKM Government Medical College, Nalhar, Haryana, INDIA. \\ ${ }^{2}$ Department of Community Medicine, Santosh Medical College, (Santosh Deemed to be University), NCR, Delhi, INDIA.
}

The Coronavirus disease (COVID-19) wreaked havoc across the globe with the onset of year 2020, which posed an extra ordinary situation in front of humankind. As the pandemic continues to progress, everyday challenges are faced by health worker in the history of mankind, because medical profession is bound by ethics our health workers are facing unprecedented ethical dilemmas and challenges in the era of COVID-19 pandemic.

Beauchamp TL and Childress JF articulated following four tenets of Biomedical ethics with which all the healthcare workers must abide Autonomy, Justice, Nonmaleficence and Beneficence. ${ }^{[1]}$ India reported a record high of 352991 daily confirmed COVID-19 cases and 2812 deaths on 25 April, according to the Johns Hopkins University database. ${ }^{[2]}$ Hospitals in India have been pleading publicly for help as they run out of oxygen. At least 20 COVID-19 patients died at the private Jaipur Golden Hospital in North West Delhi following a dip in oxygen pressure. ${ }^{[3]}$

Scarcity of Resources in India in COVID-19 Pandemic forced country to take help from other countries in this pathetic condition. The UK announced it is sending nine airline container loads of supplies to India, including 495 oxygen concentrator devices, 120 non-invasive ventilators, and 20 manual ventilators. The first shipment is to arrive in New Delhi on 27 April with further shipments to follow later in the week. ${ }^{[4]}$

Scarcity of doctors in India is also a big issue over such a huge chunk of population. World Health Organization (WHO) has promulgated desirable doctor-population ratio as 1:1,000. Yet, over 44\% of WHO Member States reported less than one physician per 1,000 population. ${ }^{[5]}$ Further, with an annual intake of 67,218 MBBS students within next 5 years, the system will add 4,70,526 MBBS doctors (from 2017) to a total of 14,93,385 by 2024 even if no new college campuses are setup with more MBBS admissions. On the other hand, India's population has been projected as 1,447,560,463 by 2024 . So, by 2024 , the doctor-population ratio is expected to be around 1.03 per 1000 population. It is clear that India will reach WHO standard of 1:1,000 doctor (only modern medicine)-population ratio within next 7 years by the current demographic trend, a year before India's $75^{\text {th }}$ independence anniversary. ${ }^{[6]}$

A huge ethical challenge had come in front of individual clinicians in not only protecting themselves but also their families, patients, and their communities. A situation of ethical quandary posed for the medical fraternity with a gigantic gap between the demand and supply of various protective medical kits such as PPE, masks, gloves, and gown. However, it is the responsibility of the administration to make them available all the necessary protective equipment without which healthcare professionals are handicapped even if they are bound with the Oath. ${ }^{[7]}$

As a general rule, all PPEs produce a significant impediment to heat loss because of their permeability that reduces evaporation. Hence, HCWs often experience increases in skin and core temperatures, which are further amplified in hot and/or humid conditions, an important factor in Indian conditions. $^{[8-10]}$

Healthcare systems all over the world have been enormously affected by the COVID-19 pandemic. Healthcare workers (HCWs) taking care of these patients need personal protective equipments (PPEs) standardized for full protection from droplets and aerosols carrying viral load to variable distances. There has been a surge of manufacturers supplying these protective gears in India and regulatory agencies have issued technical specifications pertaining to PPEs focusing solely on synthetic blood penetration tests (SBPTs) and keeping the upper limit of nonwoven fabric to $95 \mathrm{~g} / \mathrm{m}^{2}$ (GSM). These PPE specifications are silent on air permeability (AP) and water/moisture vapor transmission rate (WVTR/ MVTR) of the fabric. There is a simple acronym COMFORT (Comfort and Material Fit is an Obviously Required Test) for PPE kit, which should include the following:

(a) Body heat impact and sweating assessment for 2 hrs in an air-conditioned environment without any physical activity and assessment for sweating, dizziness, and feeling of fainting.

(b) Flexibility testing of PPE kits with assessment of ability to perform patient care and nursing activities like Ryle's tube feed, hanging intravenous fluid on bed rails, sit comfortably on chairs with knee flexion to test for tightness of fit, and tearing of fabric

(c) and any additional points which the HCW wish to give feedback about including ease of donning/doffing, need for extra ties/laces/Velcro to avoid slippage of shoe covers, etc.

They propose that comfort fit testing (Comfort and Material Fit is an Obviously Required Test) should be a part of the mandatory testing and certification process for PPE, so that the industry invests wisely in manufacturing PPE kits that are not only certified for fabric but are also tested for comfort factors. ${ }^{[11]} \mathrm{A}$ good quality of PPE kit is valuable for treating doctors, Para-medical staff and our Bearers or sweepers in the hospital.

Quarantine has been used as a preventive measure in controlling the spread of infectious diseases such as flu, cholera and plague in the past. ${ }^{[12]}$ Quarantine is the separation and restriction of movement of people who have potentially been exposed to a contagious disease for reducing the risk of them infecting others in the community. ${ }^{[13]}$ On 24 March 2020, the Government of India ordered a nationwide lockdown with potential consequences on day-to-day life, mental and physical health.

In every district there were facility quarantine centers run by district administration for housing people who are suspected to have come in contact with a confirmed case or who have travelled from an area with known COVID-19 cases. The recommended duration of quarantine for Covid-19 based on available information is up-to 14 days from the time of exposure. ${ }^{[14]}$ 


\section{Singh, et al:: Bio-ethical Challenges with COVID-19}

Many residents of such centers complained regarding food quality, poor hygienic conditions etc. while other residents also complained of discrimination and stigma of being in the quarantine centers. There were reports of people fleeing such centers and even committing suicide. ${ }^{[15]}$

In view of Autonomy of patient's the wishes which are supposed to fulfilled are not met and in view of justice Quarantine can be a necessary preventive measure during an outbreak of Pandemic situation like COVID-19, however quarantine is often associated with a negative psychological effect. Longer duration of quarantine is associated with poorer psychological outcomes; the length of quarantine should be same as the known duration of incubation period of the disease.

Authorities should ensure supplies of essential items to quarantine centres ideally in advance, with reallocation plans established to ensure resources do not run out. Authorities need to identify the immediate psychological needs of the persons staying away from their home at quarantine centres.

Normally any new vaccine development takes $10-15$ year time but the search for vaccine against SARS-CoV-2 is going on at a very fast pace resulting in almost breakthrough in vaccine development by several research institutions and vaccine manufacturers. In pandemic situation, however, the entire process of vaccine development including clinical trials gets shortened and may be fast tracked to 15-18 months' time. ${ }^{[16]}$ Normally, a vaccine goes through multiple stages before being approved for public use. Following the initial research and development stage, a vaccine is first tested on animals and then it goes through three stages of human clinical trials. In normal circumstances, each step can take two years or more to complete. However, for COVID-19 vaccines some of those phases were combined to hasten the process. For example:

Phase I: In this step, the experimental vaccine is given to humans, usually between 20-80 subjects, to test its safety and dosage besides gauging whether it stimulates the immune system. While this process typically takes one to two years, for COVID-19 trials, it was done in about three months.

Phase II: In this stage, about several hundred individuals, split into groups age-wise such as children and elderly, are dosed in a randomized, double blind, placebo-controlled study. This process usually takes about three years but for COVID-19 vaccines, it was completed in 2-3 months.

Phase III: This is the most crucial stage, where the vaccine candidate is given to thousands of people, and can typically take two to four years. However, most of the drugmakers combined this with Phase II to expedite the process.

After Phase III trials, the vaccine developer submits a license application to the regulatory authority in their respective country, and final approval may take months or years. However, in emergency situations, like the COVID-19 pandemic, authorities grant emergency-use authorization (EUA) in weeks.

"Since 1984, when the UIP was started, India has created a network of more than 26,000 cold chain points with temperature trackers for vaccines. Another crucial aspect of the supply chain is tracking the vaccine all through its transit until it is dosed. Here too, India is well equipped in the form of a software called eVIN or Electronic Vaccine Intelligence Network, which works through a smartphone application, has digital information on vaccine stocks and the temperatures in the cold chain. The software, now called Co-VIN, can also track the beneficiary and allocate a vaccination session. A QR-based digital certification is generated once a person is vaccinated and there is no adverse event. ${ }^{[17]}$
Economic independence is a critical factor in violence prevention. The COVID-19 pandemic has exacerbated financial entanglement by causing increased job loss and unemployment, particularly among women of color, immigrants, and workers without a college education. ${ }^{[18]}$

Intimate partner violence (IPV) is considered as a major public health problem across the world, and it is more commonly referred to as "domestic violence." The World Health Organization (WHO) defines IPV as "any behavior within an intimate relationship that causes physical, psychological, or sexual harm to those in the relationship." It is estimated that $30 \%$ of women, worldwide, experience some form of physical or sexual violence by their intimate partners in their lifetime. It is typically experienced by women but can also be experienced by men. ${ }^{[19]}$

Though robust data are scarce, media news and reports from the organizations, responding to domestic violence incidents, indicate that there is an alarming increase in the IPV cases during this pandemic.

Although the healthcare system, worldwide, is under tremendous pressure as the pandemic overstretched the capacity of health institutions, the health sector should still take effective measures to alleviate the risk of violence against women during the pandemic. Healthcare providers should be aware of the risks and sequel of IPV, and provide the affected subjects with psychological and social support, in addition to the necessary medical treatment. The use of telemedicine and mobile health system, to safely support those affected with IPV, must be urgently explored. ${ }^{[20]}$

Although home may be considered a safe place for some, it is not the safest place for all. In fact, with COVID-19 lockdown in place, there has been a surge in cases of domestic violence. All over the world, victims of domestic violence are more vulnerable and at risk to a frighteningly new degree of violence. Here in India, the National Commission for Women (NCW) has raised an urgent alert about the increasing number of domestic violence cases since the national lockdown began. Domestic violence involves a pattern of psychological, physical, sexual, financial and emotional abuse. Acts of assault, threats, humiliation, and intimidation are also considered acts of violence.

In addition to violation of human rights, victims of domestic violence can face several physical and mental health difficulties such as risk of chronic disease, depression, sexual disorders, PTSD (post-traumatic stress disorder) and substance abuse. Disconnection from social support systems is one of the reasons for an increased risk of domestic violence during these times. As a result, there are fewer options to find safety or help for victims. Normally, the victim could flee a violent situation by staying elsewhere, but that option is not available right now. ${ }^{[21]}$

\section{Laboring alone}

In times free of COVID-19, having 1 or more visitor is important for all patients. We have been taught the words of Hippocrates since medical school, "cure sometimes, treat often, and care always." Facilitating ongoing contact with loved ones is a critical component of caring. This is even more important in the context of childbirth. Having individuals present to attend and support a woman during her labor and delivery is not just expected but is, in fact, generally encouraged. These support people serve many important roles:

- They provide not only emotional support and encouragement but also distraction and just plain company to speed the passing of what, in some case, can be many hours. Such support, especially when knowledgeable and trained, has been associated with improved outcomes separate from 
a patient's happiness and sense of well-being.

- They can contribute to decision making, especially as parent-couples work to align choices with shared values.

- As attendants, they experience the joy of welcoming a new child.

Emotion is another factor that flavors ethical positions. As a matter of medicine, policy, and ethics, what is right here? Unlike many choices in medicine, the policy decision affects not just the patient but also other individuals including the patient's family and the healthcare team.

As is true when an individual provider is caring for a woman with known or suspected COVID-19, the risk for being infected by a visitor-partner will be mitigated by the appropriate use of PPE. The availability and type of PPE have varied widely across healthcare settings. Some require and provide masks for continuous use by HCWs and may be able to provide similar masks to patients and their partners and require that they use them continuously as well. Other facilities may limit use to the partners of patients with symptoms or known COVID-19. In cases in which masks are not worn, encouraging or even requiring distancing of the partner may offer another route of mitigation. Such distancing may be undertaken, as room architecture permits, by assigning a visitor a space appropriately distanced from where a nurse, midwife, or physician will be stationed for needed clinical care. ${ }^{[22]}$

\section{Lockdown and Divorce}

Adjustment and compromise is the foundation of any Indian marriage. It is sad but true. With the advent of the lockdown, there were quite a few changes in the lives of the married couples. Their personal spaces were getting redefined and were mostly shrinking with the couple being stuck at home. It made the acceptance or compromise much more strenuous and tricky.

A clear threefold rise in the number of divorce cases in some of the first-tier cities of India during the lockdown demonstrates the increasingly strained relations and coronavirus was a significant contributor to that. ${ }^{[23]}$

It's a scientific fact that every part of the body needs oxygen to survive. In fact, that's the main purpose of the body's respiratory system - to take in oxygen and breathe out carbon dioxide. You might, however, be surprised to learn that there's more than one type of oxygen - and two of these "alternative" types of oxygen that you may be somewhat familiar with are medical oxygen and industrial oxygen. Even more, the types of compressors that create each type of oxygen vary greatly.

A big difference between oxygen and medical oxygen. For starters, medical oxygen is a type of oxygen that is used, simply put, for medical purposes. This type of oxygen can only be generated by medical air compressors. Medical oxygen is also typically administered in non-medical situations as well. For example, athletes may take it when training or individuals may undergo oxygen therapy. The air we breathe in our atmosphere consists of about 21 percent oxygen.

So what's industrial oxygen? As the name implies, it's typically a type of oxygen used in industrial settings, like manufacturing plants, for tasks that may include combustion, oxidation and even to help accelerate certain chemical reactions. ${ }^{[24]}$

Keeping in view the rapid rise in COVID cases and resultant rapid demand for medical Oxygen, particularly in high-burden States of Maharashtra,

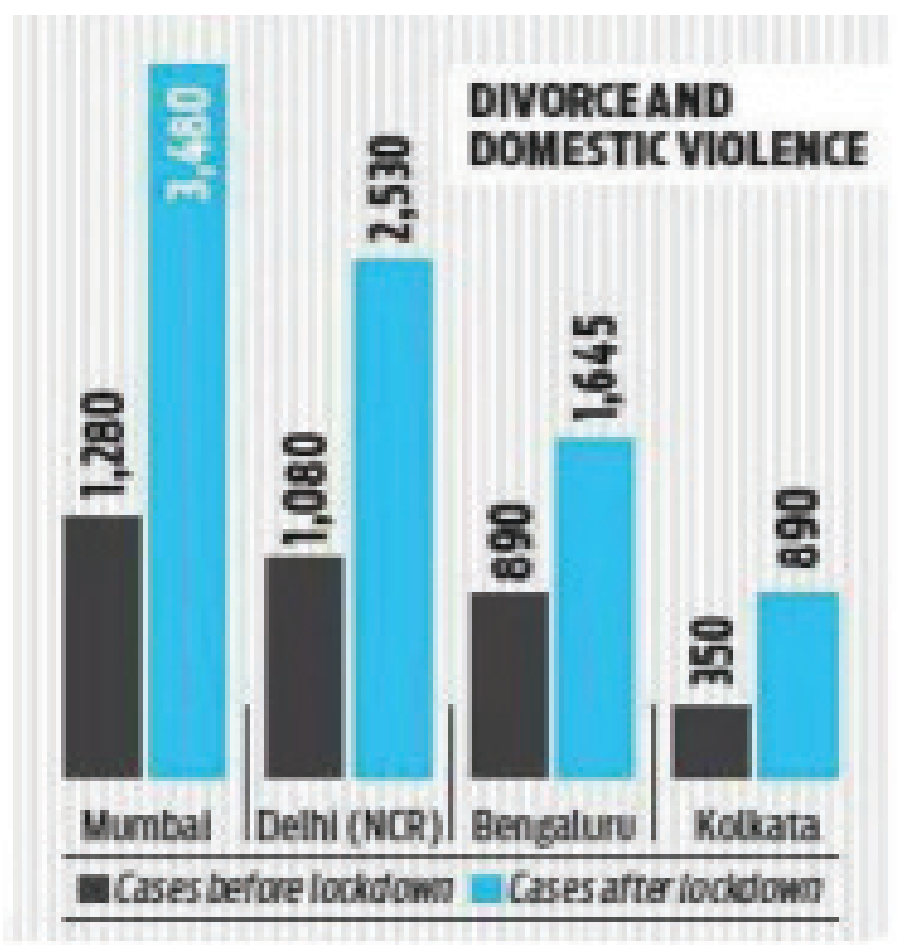

Madhya Pradesh, Gujarat, Delhi, Uttar Pradesh, Chhattisgarh, Karnataka, Kerala, Tamil Nadu, Haryana, Punjab, Rajasthan, etc., the EG-ll reviewed the supply of oxygen for industrial use in order to divert the same to meet the rising demand for medical oxygen in the country and save precious lives. "Accordingly, EG II has recommended to prohibit the supply of Oxygen for industrial purposes by manufacturers and suppliers forthwith from 22.04.2021 till further orders, with e exception of nine specified industries. ${ }^{[25]}$

\section{REFERENCES}

1. Beauchamp TL, Childress JF. Principles of biomedical ethics. 6th ed. Oxford: Oxford University Press; 2009.

2. Johns Hopkins coronavirus resource centre. India. Available from: https:// coronavirus. Available from: http://jhu.edu/region/india [cited 20/7/2021].

3. Saxena A, Sinha J. 20 die in Delhi hospital's covid critical care unit, officials say dip in oxygen, move court. India Express. Com/article/cities/delhi/delhi-jaipurgolden-hospital-covid-patientsoxygen-supply-shortage-7286997. Available from: https://indianexpress; April 252021.

4. Foreign, commonwealth, and Development Office [press release]. Uk Sends Life Saving Medical Equipment to India; April 25 2021. Available from: http://www.gov. uk/government/news/uk-sends-life-saving-medical-equipment-to-india.

5. Density of physicians (total number per 1000 population, latest available year), Global Health Observatory (GHO) data. Situation and trends.

6. Population pyramids of the world from 1950 to 2100 . Available from: https://www. populationpyramid.net/world/2019/ [cited 20/7/2021].

7. Seth AK. Bioethics: challenges in COVID-19 pandemic. J Integr Health Sci. 2020;8(1):1-2. doi: 10.4103/2347-6486.288693.

8. Hostler D, Gallagher Jr M, Goss FL, Seitz JR, Reis SE, Robertson RJ, Northington WE, Suyama J. The effect of hyperhydration on physiological and perceived strain during treadmill exercise in personal protective equipment. Eur J Appl Physiol. 2009;105(4):607-13. doi: 10.1007/s00421-008-0940-2, PMID 19037655.

9. Morley J, Beauchamp G, Suyama J, Guyette FX, Reis SE, Callaway CW, Hostler D. Cognitive function following treadmill exercise in thermal protective clothing. Eur J Appl Physiol. 2012;112(5):1733-40. doi: 10.1007/s00421-011-2144-4, PMID 21892644.

10. Koulibaly F, Maugey N, Janvier F, Foissaud V, Aletti M, et al. Moderate thermal strain in healthcare workers wearing personal protective equipment during treatment and care activities in the context of the 2014 Ebola virus disease 


\section{Singh, et al.: Bio-ethical Challenges with COVID-19}

outbreak. Gr_elot L. J Infect Dis. 2015.

11. Kapoor A, Baronia AK, Azim A, Agarwal G, Prasad N, Mishra R, Saraswat VA. Breathability and safety testing of personal protective equipment: "human-comfort" factor remains undefined. Indian J Crit Care Med. 2021;25(1):12-5. doi: 10.5005/ jp-journals-10071-23598, PMID 33603295.

12. Mandavilli A. SARS epidemic unmasks age-old quarantine conundrum. Nat Med. 2003;9(5):487. doi: 10.1038/nm0503-487, PMID 12724741.

13. CDC. Quarantine and isolation. USA; 2017. Available from: https://www.cdc.gov/ quarantine/index.html [cited 20/7/2021].

14. Guidelines for quarantine facilities COVID-19. MoHFW. Available from: https:// www.mohfw.gov.in/pdf/90542653311584546120quartineguidelines.pdf [cited 20/7/2021].

15. Why people flee quarantine. Times of India. Available from: https://timesofindia. indiatimes.com/india/covid-19-why-people-flee-quarantine.

16. Dutta AK. Vaccine Against Covid-19 Disease - Present Status of Development. Indian J Pediatr. October 2020;87(10):810-6. doi: 10.1007/s12098-020-03475-w PMID 32880819

17. 2020. How years of trials, research were compressed into months in developing a Covid-19 vaccine. Article from the Indian Express, 23 December 2020.

18. Kochhar R. Unemployment rate is higher than officially recorded, more so for women and certain other groups. Washington, DC: Pew Research Center; June 30, 2020. Available from: https://www.pewresearch.org/ facttank/2020/06/30/unemployment-rate-is-higher-than-officially-recordedmore-so-for-women-and-certain-other-groups/. opens in new tab) [cited
20/7/2021]

19. WHO. WHO Global and regional estimates of violence against women: prevalence and health effects of intimate partner violence and non-partner sexual violence. Geneva, Switzerland: World Health Organization; 2013. p. 2.

20. Roesch E, Amin A, Gupta J, García-Moreno C. Violence against women during COVID-19 pandemic restrictions. BMJ. 2020;369:m1712. doi: 10.1136/bmj. m1712, PMID 32381644.

21. Das M, Das A, Mandal A. Examining the impact of lockdown (due to COVID-19) on Domestic Violence (DV): an evidences from India. Asian J Psychiatr. 2020 December;54:102335. doi: 10.1016/j.ajp.2020.102335.

22. Ecker JL, Minkoff HL. Laboring alone? Brief thoughts on ethics and practical answers during the coronavirus disease 2019 pandemic. Am J Obstet Gynecol MFM. 2020;2(3):100141. doi: 10.1016/j.ajogmf.2020.100141.

23. Till corona do us part divorce queries rise in India; April 19, 2020. Available from: https://timesofindia.indiatimes.com/home/sunday-times/till-coronado-us-part-divorce-queries-rise-in-india/articleshow/75225320.cms [cited 20/7/2021]

24. The difference between medical oxygen \& industrial oxygen; April 6, 2021. Available from: https://jhfoster.com/compressed-air-blogs/what-is-the-differencebetween-medical-oxygen-industrial-oxygen/ [cited 20/7/2021].

25. Govt prohibits supply of oxygen for industrial purposes to meet demand for Covid patients; April 18 2021. Available from: https://www.livemint.com/news/india/ govt-prohibits-oxygen-supply-for-industrial-purposes-amid-demand-for-covidpatients-11618760896663.html [cited 20/7/2021].

Received: 12 March 2021;

Accepted: 17 May 2021;

*Correspondence to:

Dr. Abhishek Singh, Associate Professor, Department of Community Medicine, SHKM Government Medical College, Nalhar-122107, Haryana, INDIA. Phone no +917988028343 Email: abhishekparleg@gmail.com

Copyright: (C) the author(s),publisher and licensee Indian Academy of Pharmacists. This is an open-access article distributed under the terms of the Creative Commons Attribution Non-Commercial License, which permits unrestricted non-commercial use, distribution, and reproduction in any medium, provided the original work is properly cited.

Cite this article as: Singh A, Ohlan S, Agrawal D. Covid-19 Pandemic and Bio-Ethical Challenges. J Pharm Pract Community Med. $2021 ; 7(2): 20-3$. 